\title{
Does grooming facilitate the development of Stockholm syndrome? The social work practice implications
}

\author{
Shirley J. Jülich, Eileen B. Oak, Massey University, New Zealand
}

\begin{abstract}
INTRODUCTION: This article focuses on the problem of risk instrumentalism in social work and the way it can erode the relationship-based nature of practice and with it, the kinds of critical reflexivity required for remedial interventions to keep children safe.

METHOD: By exploring the relationship between the process of grooming and the condition known as Stockholm syndrome, the article seeks to address this problem by offering some concepts to inform a critical understanding of case dynamics in the sexual abuse of children which can explain the reluctance of victim-survivors to disclose.
\end{abstract}

FINDINGS: Beginning with an overview of the development of actuarial risk assessment (ARA) tools the article examines the grooming process in child sexual abuse contexts raising the question: "Is grooming a facilitator of Stockholm syndrome?" and seeks to answer it by examining the precursors and psychological responses that constitute both grooming and Stockholm syndrome.

CONCLUSION: The article identifies the underlying concepts that enable an understanding of the dynamics of child sexual abuse, but also identifies the propensity of practitioners to be exposed to some of the features of Stockholm syndrome.

KEYWORDS: Stockholm syndrome; child sexual abuse; victim-survivor; paedophile; hostage; hostage taker

\section{Introduction}

In this article, the overview of both Stockholm syndrome and grooming is explored in the context of victim-survivors and the conspiracy of silence. It is sometimes assumed that child sexual abuse victims feel unable to report abuse because of their lack of voice, lack of power, their position in the family or their inability to frame experience as abusive. However, these are not the only reasons because if it were, then as adults, these victims would surely disclose the abuse or report it to an authority, but they do not. Victim-survivors in Jülich's
(2001) study remained extraordinarily loyal and silent: a silence which persisted well into adulthood, and was so profound that victim-survivors appeared reluctant to disclose or report the sexual abuse to which they had been subjected. Their silence continued to protect the abuser long after the abuse had ceased. Jülich named this a conspiracy of silence. The reluctance to disclose and report can be attributed to attachment disorders (Bowlby, 1979) or it can be explained by Summit's (1983) child sexual abuse accommodation syndrome (CSAAS). He identified five stages of the CSAAS that
AOTEAROA

NEW ZEALAND SOCIAL WORK 28(3), 47-56.

CORRESPONDENCE TO: Eileen B. Oak E.B.Oak@massey.ac.nz 
enabled children to deal with the impact of child sexual abuse: secrecy, helplessness, entrapment and accommodation, delayed disclosure and retraction. However, though plausible in explaining the behaviour of children and young people, it does not explain why victim-survivors persist in maintaining the conspiracy of silence into adulthood. In this article we offer an explanation. We argue that grooming techniques used by those who sexually abuse children facilitates the development of Stockholm syndrome (traumatic bonding) which protects the abuser for decades. Further, we make the argument that risk instrumentalism, with its narrow definitions of risk, could inhibit the ability of professionals using ARAs to identify risk. This is exacerbated by the subtleties and complexities of the dynamics associated with the sexual abuse of children.

Before discussing the rise of neoliberal risk instrumentalism, we comment on the use of terminology. The term victim-survivor denotes a victim of child sexual abuse (CSA). Abuser denotes a perpetrator of CSA, while bystander (Herman, 1997) is used to describe family members or close family friends subjected to the complex family dynamics in the abusive situations. The term outsiders is adapted from Graham's (1994) work and refers to professionals and other people not subjected to the complex family dynamics involved in the prevention of the sexual abuse of children.

\section{The rise of neoliberal risk instrumentalism in social work}

The past twenty years have witnessed the growth of formalised risk assessment tools in child care social work in Australia, Canada, New Zealand, the UK and US (Oak, 2015). Such risk assessment instruments can be divided into two types: the formalised structured risk assessment instrument characterised, by standard questionnaires and regular templates that serve to assist professional judgement such as the "Common Assessment Framework"
(CWDC, 2006), and the actuarial riskassessment (ARA) tools in which empirical research methods are deployed to identify a series of risk factors which are believed to "have a strong statistical relationship to behavioural outcome" (Shlonsky \& Wagner, 2005, p. 410). The new Tuituia Assessment Framework (Child Youth and Family, 2013) launched in 2013 entails both the formalised assessment templates and ARA dimensions (Oak, 2015). Despite the popularity of ARAs with senior managers for the ways they are perceived to reduce practitioner bias and assist with professional judgement, they are criticised for ignoring the day-to-day client-social worker aspects of the case and hence the moral and ethical dimensions (Broadhurst et al., 2010), or to result in the erosion of rapport building skills and the kinds of reflexivity required for remedial action to protect children (Littlechild, 2008; Munro, 2011; Oak, 2015). Littlechild (2005, 2008) commented on how practitioners fail to recognise that concepts of risk are socially constructed and dynamic entities, not easily amenable to risk instrumental quantification. This problem is compounded by the fact that, when using ARAs practitioners tend to use concepts such as risk of harm and actual harm interchangeably (Gillingham, 2006). Moreover, ARAs ignores the fact that social workers need to translate risk information into a range of choices regarding the most effective service interventions (Shlonsky \& Wagner, 2005). The inability to define risk or to develop an operational definition will impact upon the practitioner's ability to determine effective thresholds for intervention (Oak, 2015). All these practice problems can be linked to the decline of the relationship-based nature of practice and the erosion of critical thinking skills as a result of the introduction of the ARAs (Broadhurst et al., 2010; Gillingham, 2006).

The problems with the types of risk instrumentalism that underpin such risk frameworks, are that they embody a specific construction of risk that is somewhat mechanistic and uniform (which belies the complex and individualised nature of the 
casework dynamics) and also entail the assumption that risk is something that can be measured, predicted and contained (HorlickJones, 2005). Given this scenario, the authors' concern is to consider what conceptual frameworks can be developed to assist practitioners develop a critical understanding of the complex, relationship dynamics that exist in child protection cases? One possible answer is to look at the relationship between Stockholm syndrome and grooming and to consider whether grooming facilitates the behaviours associated with this condition.

\section{Grooming}

Craven, Brown, and Gilchrist (2006) addressed the paucity of theorising on grooming in the context of child sexual abuse by highlighting the ways definitions of grooming such as those developed by Howitt (1995) and O'Connell (2003) conflate the term paedophile with sex offender. They identified the practice implications of this conflation by pointing out firstly, the term paedophile is a specific clinical diagnosis and most child sex offenders engage in sexual grooming not just paedophiles. Secondly, people who know the offender may not recognise the grooming process because the offender may not fit the stereotype of a paedophile and thirdly, the conflation of paedophile with sex offenders may prevent the offender recognising and taking responsibility for their grooming behaviours. These misconceptions, particularly regarding paedophile stereotypes such as "strangerdanger" detract from the fact that most child sexual abuse victim-survivors know their abuser (Cowburn \& Dominelli, 2001).

Craven et al. (2006) posited an alternative, and more holistic definition of grooming:

[A] Process by which a person prepares a child, significant adults and the environment for the abuse of a child. Specific goals involve gaining access to the child, gaining the child's compliance and maintaining the child's secrecy to avoid disclosure (p. 297).
Craven et al.'s (2006) literature review identified three types of sexual grooming: self-grooming, grooming the environment and significant others and grooming the child. Self-grooming involves the justification or denial of the offending behaviour as a precursor to the move from thinking about the act to being motivated to abuse (Van Dam, 2001). Self-grooming is likely to be affected by the response of both the wider community and the child and the success of the grooming process. It includes the cognitive distortions adopted in a similar fashion to those of victim-survivors to minimise the harm or to justify behaviour, for example, children are regarded as sex objects rather than human beings, or there is a sense of entitlement on the part of the abuser, or the behaviour is excused by the belief system "we live in a dangerous world" or it is excused by "uncontrollable urges".

Grooming the environment begins with identifying the vulnerable child (Conte, Wolf, \& Smith, 1989; Van Dam, 2001). Offenders groom the wider environment in the form of parents, carers, teachers, social workers etc. by integrating themselves into places and community networks where they are likely to have contact with children. Craven et al. (2006) commented on the ways that sex offenders exploit opportunity, in that they seek to ingratiate themselves into a community and places where they are likely to meet children and will often assume a position of trust. Van Dam (2001) reported that many descriptions of abusers amongst research respondents are that they are frequently "charming", "very helpful" and have "insider status". Another tactic is to become indispensable to the wider community. Hare and Hart (1992) suggested that abusers have a penchant for reading community needs and meeting those needs and will often willingly undertake tasks or jobs that other people will not do (Leberg, 1997).

Some abusers groom the environment by targeting lone-parent families to gain this status, or they may target children or young 
people who have absent parents, and hence have less protection. In the absence of parental role models, it is easier to befriend a child and create opportunities to be alone with them. In intrafamilial situations, abusers often isolate the victim from the non-abusing parent and the outside world by developing exclusivity with the child. They may also exploit the parents' needs for a life outside the household by encouraging them to be more proactive in community activities and at the same time this gives them increased access to their victims. Conversely, they may isolate non-abusing parents from the outside world in order to prevent them from having people with whom to share their concerns (Leberg, 1997), in a similar way to holding the child hostage (Jülich, 2005). Some abusers achieve this by encouraging drug or alcohol dependency in lone parents, which also offsets any future disclosures made which will be likely to lack credibility (Leberg, 1997). Another strategy aimed at reducing credibility is questioning (usually) the mother's parenting competence in front of friends and other family members.

The vulnerability of the community to such grooming tactics is exacerbated by the cognitive dissonance or cognitive distortions parents/carers, other family members and even professionals may experience. This dissonance/distortion manifests itself in the initial wariness and unease they have about trusting the prospective abuser which coexists with their feelings and reactions to the repeated offers of hospitality or help. Cognitive dissonance occurs when parents/carers and practitioners ignore their wariness and adopt a more appropriate response to these overtures of help and their thoughts are changed to be more consistent with behaviour (Van Dam, 2001). Grooming is a long-term strategy (Sanford, 1980) and is often undertaken so well that, even if abuse is later disclosed, the perpetrator has gained such a position of trust in the community, that the victim is unlikely to be believed.
There are two aspects to grooming the child: the physical grooming which gradually reduces the child sensitivity to touching and results in the gradual sexualisation of the child (Berliner \& Conte, 1990) and psychological grooming which may begin with the abuser's version of "sex education" or attempts to enter a child's bedroom when they are changing or stroking a child's head when discussing explicit sexual material. Such attempts to normalise this sexualised behaviour are assisted by the roles that abusers adopt to legitimate their actions, for example, Herman et al.'s (1990) study identified how abusing fathers adopted the role of "suitor" to the daughters they abused. Another technique is the effort to interact with the child on their "wave-length" (Van Dam, 2001) or raising the child's status to that of adult (Wilson, 1999).

Chase and Statham (2005) identified a four stage continuum to the grooming process: stage 1: identify the vulnerable child, stage 2: socially isolate the child, stage 3: develop an emotional attachment, and stage 4: isolate the child from their families and develop progressive control over the child. The study of child sex offenders by Elliott, Browne, and Kilcoyne (1995) demonstrated how groomers looked for specific behaviours to identify vulnerability, such as the way the young person was dressed, whether they lacked confidence and self-esteem, or whether they had a problematic relationship with parents/ carers. Similarly, Ward and Keenan (1999) explored the distal planning strategies of groomers and describes two types; covert/ explicit planning - the abuser/offender does not acknowledge any premeditated thought or planning but, manipulates circumstances in order to enhance contact with potential victims and explicit planning - deliberately initiating contact for sexual purposes. This is similar to techniques used by hostage takers (Graham et al., 1994)).

Several researchers (Finkelhor, 1984; Prentky, Knight, \& Lee, 1997; Wyre, 1987) identified 
three typologies of groomer: the aggressive groomer whose approach is characterised by violence, threat or force (Gupta, Raj, Decker, Reed, \& Silverman, 2009); the criminal opportunist, those who engage in one-off offences against strangers; and the intimate groomer who perceives a relationship with their victims as analogous to a consenting sexual relationship between two adults (Canter, Hughes, \& Kirby, 1998) and where intimacy is ensured through the promise of gifts, reassurance, affection, desensitisation, kissing and oral sex by abuser on victim. A fourth dimension of grooming is suggested by McAlinden (2012) who described a style of grooming known as "forbidden fruit" activities where groomers use items or treats that are illegal for children or young people to consume such as alcohol, cigarettes and drugs, the showing of (adult and child) pornography and telling lewd jokes. Forbidden fruit activities, by their deviant nature, are likely to ensure the compliance of children and to reduce the likelihood of disclosure.

Just as an understanding of grooming techniques is vital to understand the processes through which CSA occurs, Williams (2015) asserted that an understanding of pre-offence grooming is equally important, because it provides insights into the ways a perpetrator manipulates the behaviour of the victim and changes the relationship to an overtly abusive one (Berliner \& Conte, 1990). Thus it is necessary to understand how victims are approached and groomed as part of their routine activities (Felson, 2008) and how the manipulation and control occurs. This power and control is further secured through the construction of trauma bond that some victim-survivors form with their perpetrators through a process of violence counterpoised with affection and degradation (Jordan, Patel, \& Rapp, 2013). This is similar to the small kindness being amplified in the context of terror, identified in Jülich's (2001) research as a precursor to Stockholm syndrome.

\section{The relevance of Stockholm syndrome}

Stockholm syndrome is a useful concept as it can provide an over-arching understanding of why victim-survivors of child sexual abuse have acted and responded as they do. This phenomenon is also referred to as traumatic bonding, hostage identification syndrome, or survival identification syndrome. Stockholm syndrome is named after the robbery of Kreditbanken at Norrmalmstorg in Stockholm, Sweden in 1973. During the crime, several bank employees were held hostage in a bank vault from August 23 to 28, 1973, while their captors negotiated with police. It has been accepted that hostages can develop Stockholm syndrome and we have many examples of this beginning with the puzzling reactions of employees in the Stockholm bank (Graham et al., 1994). During six days of captivity, the hostages (bank staff: three women, one man) developed an emotional bond to the hostage takers. This was a complex bidirectional bond that formed the basis of a survival strategy for the hostages. They believed if the hostage takers liked them, then they would not hurt them. This relationship persisted well beyond the siege and the hostages continued to view the hostage takers as their protectors, and were unable to censure them in any way. The emotional bond with the hostage-takers was so powerful they not only identified with the hostage-takers but also came to view the police as the enemy. Subsequently, the hostages attempted to protect the hostage takers from the police (Goddard \& Tucci, 1991; Graham et al., 1994). The relationship between the hostages and hostage-takers did not cease at the end of siege but persisted for years after the actual incident. Moreover, the female member of staff formed an intimate relationship with one of the hostage takers (Jameson, 2010).

The reactions of hostages in this event, and other similar instances, have been studied to provide the basis for what has come to be known as classic Stockholm 
syndrome (Graham et al., 1994; Hacker, 1976; Kuleshnyk, 1984; Soskis \& Ochberg, 1982; Strentz, 1982). Drawing on the literature related to hostages, Graham et al. (1994) extended classic Stockholm syndrome to provide an overarching theory referred to as Graham's Stockholm syndrome theory. Graham and her colleagues theorised that emotional bonding could occur between a victim and an offender and reviewed the literature relating to nine victimised groups to determine whether bonding to an offender occurred as it had in Stockholm syndrome. These groups included concentration camp prisoners, cult members, and civilians in Chinese Communist prisons, pimp-procured prostitutes, incest victims, physically and/ or emotionally abused children, battered women, prisoners of war, and hostages in general. It was found that in all nine groups, bonding between an offender and a victim occurred when the four following conditions co-existed: (a) perceived threat to survival and the belief that one's captor is willing to carry out that threat; (b) the captive's perception of some small kindness from the captor within a context of terror; (c) isolation from perspectives other than those of the captor; and (d) perceived inability to escape (Graham et al., 1994, p. 33). All these factors were identified in Jülich's (2001) research as precursors to the development of Stockholm syndrome. Jameson (2010) explored the psychology of Stockholm syndrome and described it as both a survival strategy and form of adaptive behaviour which provides hope for the victim in a hopeless situation. Seen in this context it is easy to understand how victim-survivors of child sexual abuse form strong emotional attachments to their abusers and misconstrue small acts of kindness as love.

While the general public would not think of children and young people as hostages, they can be victims and they can be held captive, and in chronic abusive relationships they are particularly vulnerable to the forces of Stockholm syndrome which can be understood as a survival technique for children in this situation. Victims of child sexual abuse are more likely to develop Stockholm syndrome (Alvarez \& Alessi, 2012). Their hostage situation exists in both material and subliminal form manifested in: their perceived threat to survival and belief the abuser is willing to carry out that threat, the victim's perception of some small kindness from the abuser within a context of terror, fear of isolation and the perceived inability to escape. These elements are the four precursors or conditions that Graham et al. (1994) identified as the precursors for Stockholm syndrome and Jülich (2001) analysed her interviews of adult survivors of CSA using these precursors as a framework.

Emotional abuse or the threat of harm is a threat to physical survival. Child sexual abuse (CSA) includes physical and emotional abuse which threatens a child's psychological survival and in some cases his/her physical survival. Adult victimsurvivors of CSA in Jülich's (2001) study indicated they had experienced threats in many different ways - physical, sexual, the withdrawal of love, threats that people they loved might be harmed or pets harmed. A person under threat perceives kindness differently than a person who has not been threatened, as is the case for instance, in the cessation of violence experienced by battered women. Victim-survivors spoke about physical sensations that were enjoyable, they often prefaced statements with "at least he didn't" and ended with "hurt my sister/ brother/mother "etc. They often said "it wasn't that bad", "or it could have been worse" (Jülich, 2001, p. 183).

Isolation is not as obvious for victims of CSA as in other hostage taking situations. However, the emotional and psychological isolation described by adult victim-survivors of child sexual abuse in Jülich's (2001) research was profound. For some this was reinforced by the lack of action by various authorities (outsiders). Victim-survivors said they blamed themselves, they felt guilty, and were ashamed, and this alone served to isolate them from the perspectives of others (Jülich, 2001). This situation is exacerbated 
by threats abusers make to children as they silence them and which renders them incapable of escape. The victim-survivors in Jülich's research said they tried to stop the abuse but were unable to. Other adults (bystanders) who should or could have known what was happening did nothing. All too often in those cases when reports or disclosures were made, the abuse did not stop. Some mothers were unable to protect victim-survivors because they were subjected to abuse as well. Victim-survivors interpreted this as proof that there were unable to escape (Jülich, 2001).

Advocates of Stockholm syndrome theory would argue that, given these precursors Stockholm syndrome can develop. However, we argue that grooming can also facilitate the development of Stockholm syndrome.

\section{Subliminal messages of Stockholm syndrome and grooming}

The subliminal messages associated with Stockholm syndrome lead victims to have narrowed perceptions: they are focused on the immediate, surviving in the here and now and, as a result, cognitive distortions distortions or dissonance occurs. Such distortions are evident in their reframing of the situation where they do not see themselves as abused when actually they are, or they minimise and rationalise the abuse e.g., - "it wasn't that bad", or the abuser "couldn't help him/herself ". Often they blame themselves or they see the abuser as "good "and themselves as "bad" or they switch back and forth. They frequently interpret violence as a sign of caring and love and demonstration of small kindnesses in a context of chronic abuse, become large kindnesses and enable victims to have hope for the future. In extreme cases they believe they love the abuser and they are convinced they need the abuser's love to survive.

Finally they become convinced that the abuser will know if they have been disloyal and will "get them" or that they will retaliate in some way. Subliminal messages to grooming are very similar: victim-survivors feel they are to blame, they are bound to the abuser through secrecy, or they think the abuser is the only one who understands them, or they feel that the abuser treats them like a grownup, and in some cases victims want to "protect" the abuser (Jülich, 2001).

Cognitive distortions can generate a sense of false or pseudo agency in victim-survivors. The pretend or pseudo-agency in this instance, refers to the ways child sex abusers lull victims into thinking they are giving informed consent and that they are engaged in a sexual relationship with an equal when in fact they are victims-survivors of CSA. Thus, the victim feels as though they are in control and making informed decisions about the relationship, not only as children but well into adulthood. They are unable to see the relationship as abusive, they might know on some level that it is wrong but they become incredibly practised at maintaining the silence. Conte et al. (1989) identified in their research with convicted child sex abusers that the development of pseudoagency was a popular grooming tactic with young victims.

\section{Implications for assessing risk and abuse}

The complex bidirectional relationship central to Stockholm syndrome could still be very strong according to where the victimsurvivor is on his/her journey of recovery. This relationship does break down, but it takes time. Victim-survivors of CSA when they are prepared to disclose, will appear to practitioners as ambivalent and even contradictory, they may tell their story then recant (part of the process of child sexual abuse accommodation syndrome, but also an anticipated outcome of exposure to the precursors of Stockholm syndrome). Therefore it can be frustrating to work with victims of child sexual abuse as they seem to keep changing their minds, and practitioners may start to doubt them and doubt themselves and their understanding of what is happening or has happened. Thus they need to be mindful that support 
persons (bystanders) can be subjected to the same forces the abused child was, and that they too could be subjected to the influence of Stockholm syndrome and grooming. Moreover, victims may not be confident that family members (bystanders) or professionals (outsiders) can contribute objectively. Often family members are the very people who should have been able to protect the child, but they did not for whatever reason. Herman (1997) has reminded us that bystanders traditionally have "looked the other way", and "outsiders" (professionals) too have failed to recognise the signs of chronic child sexual abuse. It is also pertinent to remind ourselves that as practitioners, social workers working in families are not immune to the development of Stockholm syndrome. There has been some research in Australia indicating that social workers could use the same techniques as children when dealing with a potentially violent parent (Goddard \& Tucci, 1991), while in the UK, research has shown the impact of Stockholm syndrome has led child protection practitioners to reframe violence and sexual abuse as something else (Littlechild, 2008; Munro, 2011), or become susceptible to cognitive dissonance in relation to prospective abusers (Munro, 2011).

\section{Conclusion: Conceptual frameworks to inform social work practice?}

This article has explored the connection between grooming and Stockholm syndrome in order to provide an explanation for nonreporting of CSA and to identify the common relationship dynamics that develop in both scenarios so as to inform the relationship based aspects of social work practice. In doing so, it has attempted to provide a brief overview of the psychology and behavioural characteristics of abusers and hostagetakers and to identify how certain forms of vulnerability and opportunity increase the likelihood of abuse occurring. Moreover, it provided a range of research evidence to support the developing of Stockholm syndrome as a result of CSA grooming (Graham et al, 1994: Julich, 2001). As a result, it has identified numerous ways this connection can inform social work practice. In terms of grooming, Ost (2004) suggested that developing grooming typologies informs practice because they have the potential (if not to predict) to identify certain regular patterns of behaviour and motive so as to develop a modus operandi of an abuser who has had previous convictions for CSA. Elliott et al. (1995) identified a number of core grooming typologies for framing the complex dynamics of abusive relationships and for enabling comparisons between different, yet connected categories of abusive behaviour. In terms of Stockholm syndrome and grooming there are further similarities between the distal planning strategies used by hostage takers and abusers, the targeting of victims and the ways opportunities are exploited to gain access (Gupta et al., 2009; Ward \& Keenan, 1999). Moreover, Craven et al.'s (2006) tripartite model of grooming, including reference to how abusers groom the environment, coupled with the concept of cognitive distortions, offer insights into the ways child protection practitioners could become susceptible to elements of Stockholm syndrome.

Whilst none of these conceptual frameworks could be regarded as constituting a body of knowledge to generate a precise science, they do render a more critical understanding of the power plays at the centre of these abusive relationships and hence contribute to an understanding of casework dynamics in child sexual abuse contexts. These dynamics do not readily lend themselves to the kinds of risk instrumentalism underpinning ARAs like the Tuituia Assessment Framework and hence these concepts are vital to the development of a critical practice aimed at remedial interventions to protect children. Indeed, if certain conditions and the four precursors identified by Graham et al. (1994) exist, Stockholm syndrome may be present. It is likely this will not be identified on an ARA instrument. 


\section{References}

Alvarez, M. B., \& Alessi, E. J. (2012). Human trafficking is more than sex trafficking and prostitution: Implications for social work. Affilia, 27(2), 142-152. doi: $10.1177 / 0886109912443763$

Berliner, L., \& Conte, J. R. (1990). The process of victimization: The victims' perspective. Child Abuse \& Neglect, 14(1), 29-40. doi: http://dx.doi.org/10.1016/0145-2134(90)90078-8

Bowlby, J. (1979). The making and breaking of affectional bonds. New York: Brunner-Routledge.

Broadhurst, K., Hall, C., Wastell, D., White, S., \& Pithouse, A. (2010). Risk, instrumentalism and the humane project in social work: Identifying the informal logics of risk management in children's statutory services. British Journal of Social Work, 40(4), 1046-1064. doi: 10.1093/ bjsw/bcq011

Canter, D., Hughes, D., \& Kirby, S. (1998). Paedophilia: Pathology, criminality, or both? The development of a multivariate model of offence behaviour in child sexual abuse. The Journal of Forensic Psychiatry, 9(3), 532555. doi: 10.1080/09585189808405372

Chase, E., \& Statham, J. (2005). Commercial and sexual exploitation of children and young people in the UK: A review. Child Abuse Review, 14(1), 4-25. doi: 10.1002/ car.881

Child Youth and Family. (2013). The Tuituia assessment framework guidelines. Retrieved July 19, 2016, from http://www.practicecentre.cyf.govt.nz/policy/assessmentand-decision-making/resources/the-tuituia-assessmentframework-guidelines.html

Conte, J. R., Wolf, S., \& Smith, T. (1989). What sexual offenders tell us about prevention strategies. Child Abuse \& Neglect, 13(2), 293-301. doi: http://dx.doi. org/10.1016/0145-2134(89)90016-1

Cowburn, M., \& Dominelli, L. (2001). Masking hegemonic masculinity: Reconstructing the paedophile as the dangerous stranger. British Journal of Social Work, 31(3), 399-415. doi: 10.1093/bjsw/31.3.399

Craven, S., Brown, S. J., \& Gilchrist, E. (2006). Sexual grooming of children: Review of literature and theoretical considerations. Journal of Sexual Aggression, 12(3), 287-299. doi: 10.1080/13552600601069414

CWDC. (2006). The common assessment framework for children and young people: A guide for practitioners. Retrieved from http://www.plymouth.gov.uk/caf_for_ practitioners_national_guidance.pdf

Elliott, M., Browne, K., \& Kilcoyne, J. (1995). Child sexual abuse prevention: What offenders tell us. Child Abuse \& Neglect, 19(5), 579-594. doi: http://dx.doi. org/10.1016/0145-2134(95)00017-3

Felson, M. (2008). Routine activity approach. In R. Wortley, \& L. Mazerolle (Eds.), Environmental criminology and crime analysis (pp. 70-77). Cullompton, UK: Willan Publishing.

Finkelhor, D. (1984). Child sexual abuse: New theory and research. New York: Free Press.

Gillingham, P. (2006). Risk assessment in child protection: Problem rather than solution? Australian Social Work, 59(1), 86-98. doi: 10.1080/03124070500449804

Goddard, C., \& Tucci, J. (1991). Child protection and the need for the reappraisal of the social worker-client relationship. Australian Social Work, 44(2), 3-10. doi: 10.1080/03124079108550106
Graham, D. L. R., with Rawlings, E. I., \& Rigsby, R. K. (1994). Loving to survive: Sexual terror, men's violence and women's lives. New York: New York University Press.

Gupta, J., Raj, A., Decker, M. R., Reed, E., \& Silverman, J. G. (2009). HIV vulnerabilities of sex-trafficked Indian women and girls. International Journal of Gynecology \& Obstetrics, 107(1), 30-34. doi: http://dx.doi.org/10.1016/j. ijgo.2009.06.009

Hacker, F. J. (1976). Crusaders, criminals and crazies: Terror and terrorism in our time. New York: Bantam.

Hare, R. D., \& Hart, S. D. (1992). Psychopathy, mental disorder, and crime. In S. Hodgins (Ed.), Mental disorder and crime. (pp. 104-115). Newbury Park, CA: Sage Publications, Inc.

Herman, J. L. (1990). Sex offenders: A feminist perspective. In W. L. Marshall, D. R. Laws, \& H. E. Barbaree (Eds.), Handbook of sexual assault: issues, theories, and treatment of the offender (pp. 177-193). New York: Plenum Press.

Herman, J. L. (1997). Trauma and recovery: The aftermath of violence - from domestic abuse to political terror. London: Basic Books.

Horlick-Jones, T. (2005). Informal logics of risk: Contingency and modes of practical reasoning. Journal of Risk Research, 8(3), 253-272. doi: 10.1080/1366987042000270735

Howitt, D. (1995). Paedophiles and sexual offences against children. Oxford, UK: John Wiley and Sons.

Jameson, C. (2010). The "short step" from love to hypnosis: A Reconsideration of the Stockholm Syndrome. Journal for Cultural Research, 14(4), 337-355. doi: 10.1080/ 14797581003765309

Jordan, J., Patel, B., \& Rapp, L. (2013). Domestic minor sex trafficking: A social work perspective on misidentification, victims, buyers, traffickers, treatment, and reform of current practice. Journal of Human Behavior in the Social Environment, 23(3), 356-369. doi: 10.1080/10911359.2013. 764198

Jülich, S. (2001). Breaking the silence: Restorative justice and child sexual abuse. (PhD Thesis), Massey, Albany. Retrieved from http://mro.massey.ac.nz/handle/10179/2110

Jülich, S. (2005). Stockholm syndrome and child sexual abuse. Journal of Child Sexual Abuse, 14(3), 107-129. doi: 10.1300/J070v14n03 06

Kuleshnyk, I. (1984). The Stockholm Syndrome: Toward an understanding. Social Action and the Law, 10(2), 37-42.

Leberg, E. (1997). Understanding child molesters: Taking Charge. Thousand Oaks, CA: Sage Publications, Inc.

Littlechild, B. (2005). The nature and effects of violence against child-protection social workers: Providing effective support. British Journal of Social Work, 35(3), 387-401. doi: 10.1093/bjsw/bch188

Littlechild, B. (2008). Child protection social work: Risks of fears and fears of risks - Impossible tasks from impossible goals? Social Policy \& Administration, 42(6), 662-675. doi: 10.1111/j.1467-9515.2008.00630.x

McAlinden, A.-M. (2012). 'Grooming' and the sexual abuse of children: Institutional, internet, and familial dimensions. Oxford: Oxford University Press.

Munro, E. (2011). The Munro review of child protection: Final report - A child-centred system. UK: Department for Education. Retrieved from https://www.gov.uk/ government/uploads/system/uploads/attachment_data/ file/175391/Munro-Review.pdf 
O'Connell, R. (2003). A typology of cyber sexploitation and online grooming practices. Lancashire: Cyberspace Research Unit, University of Central Lancashire. Retrieved from http://image.guardian.co.uk/sys-files/ Society/documents/2003/07/17/Groomingreport.pdf

Oak, E. (2015). A minority report for social work? The Predictive Risk Model (PRM) and the Tuituia Assessment Framework in addressing the needs of New Zealand's vulnerable children. British Journal of Social Work. doi: 10.1093/bjsw/bcv028

Ost, S. (2004). Getting to grips with sexual grooming? The new offence under the Sexual Offences Act 2003. Journal of Social Welfare and Family Law, 26(2), 147159. doi: $10.1080 / 014180304200023088$

Prentky, R. A., Knight, R. A., \& Lee, A. F. S. (1997). Child sexual molestation: Research issues. Washington: U.S Department of Justice, Office of Justice Programs. Retrieved from https://www.ncjrs.gov/pdffiles/163390.pdf

Sanford, L. T. (1980). The silent children: A parent's guide to the prevention of child sexual abuse. New York: McGraw-Hill.

Shlonsky, A., \& Wagner, D. (2005). The next step: Integrating actuarial risk assessment and clinical judgment into an evidence-based practice framework in CPS case management. Children and Youth Services Review, 27(4), 409-427. doi: http://dx.doi.org/10.1016/j. childyouth.2004.11.007

Soskis, D. A., \& Ochberg, F. M. (1982). Concepts of terrorist victimization. In D. A. Soskis, \& F. M. Ochberg (Eds.), Victims of terrorism (pp. 105-135). Boulder CO: Westview Press.

Strentz, T. (1982). The Stockholm syndrome: Law enforcement policy and hostage behaviour. In F. M. Ochberg, \& D. A. Soskis (Eds.), Victims of terrorism (pp. 149-163). Boulder CO: Westview Press.

Summit, R. (1983). The child sexual abuse accommodation syndrome. Child Abuse and Neglect, 7(2), 177-193. doi: 10.1016/0145-2134(83)90070-4

Van Dam, C. (2001). Identifying child molesters: Preventing child sexual abuse by recognizing the patterns of offenders. New York: Haworth Maltreatment and Trauma Press.

Ward, T., \& Keenan, T. (1999). Child molesters' implicit theories. Journal of Interpersonal Violence, 14(8), 821-838. doi: 10.1177/088626099014008003

Williams, A. (2015). Child sexual victimisation: Ethnographic stories of stranger and acquaintance grooming. Journal of Sexual Aggression, 21(1), 28-42. doi: $10.1080 / 13552600.2014 .948085$

Wilson, R. J. (1999). Emotional congruence in sexual offenders against children. Sexual Abuse: $A$ Journal of Research and Treatment, 11(1), 33-47. doi: 10.1023/a:1021328828666

Wyre, R. (1987). Working with sex offenders. Oxford: Perry Publications. 